\title{
Aislamiento, purificación y selección de bacterias como candidatos para ser utilizadas en procesos de biorremediación de Mancozeb (ethylenebisdiothio carbamate) utilizado en cultivos depapa ${ }^{1}$
}

\author{
Miguel A. Piragauta $A^{* 2}$,, \\ Martha L. Mojica ${ }^{3}$ y Edgar G. Baquero 4 \\ Laboratorio de Microbiología Facultad del Medio Ambiente \\ y Recursos Naturales. \\ Centro de investigaciones y Desarrollo Cientifico CIDC, \\ Universidad Distrital FJC,
}

\section{RESUMEN}

De 28 muestras de suelo provenientes de cultivos de papa, se aislaron 69 colonias de bacterias diferentes en Caldo Nutritivo con Mancozeb $(0,0625 \mathrm{mg} / \mathrm{ml})$. Las cepas aisladas, se cultivaron por $24 \mathrm{~h}$ a $25^{\circ} \mathrm{C}$ en caldo Sales, suplementado con fuentes de carbono (glucosa $0,1 \%$ ), nitrógeno (nitrato de potasio $0,2 \%$ ) o sin ellos y mancozeb (Dithane M45 NT) a concentraciones de $0.0625 \mathrm{mg} / \mathrm{ml}$, seleccionando 3 cepas promisorias, las cuales fueron cultivadas en caldo SGNM por 72h. La cepa de P putida presento el mejor comportamiento en este medio de cultivo hasta las $72 \mathrm{~h}$, indicando posible uso del mancozeb como fuente adicional de carbono. La actividad biológica de la cepa de

1 Proyecto Financiado por el Centro de Investigaciones y Desarrollo Científico. Universidad Distrital Francisco José de Caldas

2 M. Sc. Microbiología. Director del proyecto de investigación. Docente tiempo completo. Universidad Distrital Francisco José de Caldas. Facultad dèl Medio Ambiente y Recursos Naturales. Proyecto Curricular de Tecnología en Saneamiento Ambiental. *Av. Circunvalar Venado de oro, Tel.3424706, mpiragauta@udistrital.edu:co.

3 Ingeniera Sanitaria. Docente tiempo completo. Universidad Distrital Francisco José de Caldas. Facultad del Medio Ambiente y Recursos Naturales. Proyecto Curricular de Tecnología en Saneamiento Ambiental.

4 Tecnólogo En Saneamiento Ambiental. Participo en el proyecto como pasante de investigación. 
Pseudomonas putida sobre el mancozeb, se determinó utilizando una cepa de Bacillus cereus sensible al mancozeb como indicador de concentraciones residuales de mancozeb en los medios de digestión; se detectó que en 24 horas la cepa de P. putida con una población inicial de $10^{6}$ células $/ \mathrm{ml}$, degradó el mancozeb de $0,0625 \mathrm{mg} / \mathrm{ml}$ a $0,0025 \mathrm{mg} /$ $\mathrm{ml}$. La rapidez de degradación del mancozeb con una población de P. putida baja, la presenta como promisoria para usos en biorremediación de suelos.

Palabras Clave:

Mancozeb control de Phytophtora infestans, biorremediación de pesticidas en cultivo de papa, Pseudomonas putida.

\section{ABSTRACT:}

* 69 colonies of different bačtéria were isölated in culture medium with mancozeb $(0.0625 \mathrm{mg} / \mathrm{ml})$. They came from 28 samples of soil of potato crops. The isolated strains were cultivate for 24 hours at a temperature of $25^{\circ} \mathrm{C}$ in salts broth, which was supplemented with sources of carbon' (glucose $0.1 \%$ ), nitrogen (potassium nitrate $0.2 \%$ ) or without them and also with mancozeb (Dithane M $45 \mathrm{NT}$ ) in concentration of $0.0625 \mathrm{mg} / \mathrm{ml}$. Out of those 69 samples were selected and cultivate in this SGNM broth for 72 hours, indicating possible use of mancozeb as an additional source of carbon. The biological activity of the strain called Pseudomonas putida upon manicozeb was determined using a strain of Bacillus cereus sensitive to mancozeb as a indicator of residual concentration of mancozeb in the digestion means. It was detected that in $24 \mathrm{~h}$ the strain P. putida with an initial population of $10^{6}$ cells $/ \mathrm{ml}$ degraded the mancozeb from $0.0625 \mathrm{mg} / \mathrm{ml}$. The speed of degradation of the mancozeb with low P. putida population makes it promising for use in bioremediation of soil.

\section{Keywords:}

Mancozeb, bioremediation of pesticide in potatoes crop, Pseudomonas putida, Phytophtora infestans

\section{INTRODUCCIÓN}

El mancozeb es un insecticida utilizado para el control de plágas que afectan cultivos, como el caso del hongo Phytophtora infestans, que causa la gota de la papa. En Colombia se usa en forma generalizada en las zonas de Cundinamarca, Boyacá, Nariño y otros departamentos, donde el cultivo de papa es extensivo y se aplica varias veces en el año por ciclo de producción con una frecuencia de 7.2 ( 2 a $5 \mathrm{~kg} / \mathrm{ha}$ ), siendo de mayor intensidad en las épocas de lluvias (cada 7 a 10 días) (FRENO y TÉLLEZ 1997; FEDEPAPA 1997; HOUETO AND HOFFMAN, 1995; CORPOICA, 2001). Este fungicida es un carbamato y su compuesto activo es un producto polimérico de Manganeso etilen-1,2-bisditiocarbamato, en coordinación con iones de zinc, conocido en el comercio como: Dithane M 45, Dithane F-MB líquido, Manzate 200. Ridomil, Veranero, Vondoceb, Cursate M8 y Sandofan M10. Cobrethane, Curatane, Acrobat MZ, Mancozeb, Mancozin, Manzate 200, Manzeb, entre otros (FEDEPAPA, 
1997|. A pesar de su clasificación toxicológica en categoría III por legislaciones flexibles y de bajo control en el mundo, existen referencias que reportan un alto riesgo de toxicidad aguda y crónica en animales experimentales (EXTOXNET, 1998) debido al metabolito Etilentiourea de toxicidad categoría I, carcinogénico, mutagénico y teratogénico presentando riesgos para la salud humana, de mamíferos en general y de peces (XU SUE, 2000; CALUMPANG, et. al., 1993). Al aplicarse por aspersión y debido a la alta incidencia de vientos en la región por deriva puede llegar a contaminar afluentes. En el suelo forma residuos no extractables, pero la etilentiourea se lixivia contaminando aguas subterráneas. En el tubérculo de la papa se han reportado residuos de mancozeb de $0,0233 \mathrm{ng} / \mathrm{kg}$ de papa (CORPOICA, 2001).

La permanencia del mancozeb en el suelo es de 1 a 7 días y la frecuencia dẹ aspersión en muchos de los casos es cada 7 días en épocas de lluvia, razón por la cual es importante la búsqueda de biotransformadores de este compuesto para utilizarse como biorremediadores de suelos contaminados (CALUMPANG, et. al., 1993; CORPOICA, 2001; GONZALEZ, 2003.). Este reporte presenta los resultados de la búsqueda de bacterias aeróbicas heterótrofás provenientes de muestras de suelo de cultivo de papa de Cundinamarca y Boyacá que presèntan actividad transformadora de mancozeb en cultivo líquido con médio mínimo y presencia de mancozeb a una concentración de $0.0625 \mathrm{mg} / \mathrm{ml}$. La detección de la actividad degradadora de una cepa de Pseudomonas putida se determinó indirectamente usando una cepa de Bacillus cereus sensible a mancozeb.

\section{MATERIALES Y MÉTODOS}

\section{1 Consecución de muestras de suelo para aislamiento de microorganismos degradadores de mancozeb}

Se colectaron 20 muestras de $500 \mathrm{~g}$ cada una, provenientes de Zipaquirá en las veredas de Venta Larga, Río Frío, Páramo del Guerrero y Páramo Alto, municipio de Cogua y Villapinzón en Cundinamarca y 8 muestras en el municipio de Caldas, Boyacá. Las muestras se recolectaron hasta una profundidad de $10 \mathrm{~cm}$ con una pala metálica y se empacaron en bolsas plásticas estériles. Se transportaron en nevera de icopor hasta el laboratorio de microbiología y se mantuvieron a $4{ }^{\circ} \mathrm{C}$ hasta su uso.

\subsection{Aislamiento de bacterias en presencia de mancozeb}

En una fiola con $99 \mathrm{ml}$ de caldo nutritivo estéril y $0.0625 \mathrm{mg} / \mathrm{ml}$ de mancozed fresco (Dithane M-45 NT al 80\% de mancozeb) se disolvieron $11 \mathrm{~g}$ de muestra de suelo, se incubó a $25^{\circ} \mathrm{C}$ con agitación constante en un agitador magnético (Agitador Stirrer/ Hot plates CORNING) con plancha de calentamiento a $170 \mathrm{rpm}$ durante $48 \mathrm{~h}$. Seguidamente se recolectó un inoculo de $100 \mu$ l y se extendió en la superficie de agar nutritivo en caja con asa de vidrio. Las cajas fueron incubadas a $25^{\circ} \mathrm{C}$ por 48 horas en estufa (BINDER) . A cada una de las colonias crecidas en estas cajas se les describió su morfología macroscópica y microscópica. Se realizó un tamizaje seleccionado las colonias con morfologías diferentes y se resembró utilizando la técnica de aislamiento 
en placa de agar nutritivo con incubación a $25^{\circ} \mathrm{C}$ por $48 \mathrm{~h}$. Las cepas puras se guardaron en nevera a $4^{\circ} \mathrm{C}$.

\subsection{Dinámica de crecimiento de las cepas $2-2,6-3$ y 8-3 en cultivo estático durante 72 horas en medio de cultivo SGNM.}

De cultivos en Agar Nutritivo (AN) con las cepas 2-2, 6-3 y 8-3 que presentaron características promisorias como degradadoras de mancozeb (datos no mostrados) se tomaron alícuotas de $100 \mu \mathrm{l}$ de cada una y por separado se sembraron en tubos con $9 \mathrm{ml}$ de de caldo de cultivo liquído.SGNM (Cloruro de sodio $\mathbf{0 , 3 0 \%}$, cloruro de potasio $0,02 \%$, sulfato de magnesio $0,01 \%$, fosfato mono potásico $0,15 \%$, fosfato dipotásico $0,40 \%$, glucósa $0.1 \%, 0,2 \%$ de nitrato de potasio y 0,0625 $\mathbf{m g} / \mathbf{m l}$ de mancozeb) (Manual OXOID. 1995). Este primer tubo de cada una de las cepas se denominó como Tubo 1.

El Tubo 1, se incubó 24 horas a $25^{\circ} \mathrm{C}$. Pasado el tiempo de incủbación se realizó conteo directo en cámara de Neubauer y de este se pasaron $100 \mu \mathrm{l}$ a otro tubo con $9 \mathrm{ml}$ de SGNM (Tubo 2). Cuando el Tubo 1 completo 48 horas de incubación a $25^{\circ} \mathrm{C}$ nuevamente se realizó conteo directo y se sembró en $9 \mathrm{mI}$ de SGNM (Tubo3). Este proceso se repitió cuando el Tubo 1 completo 72 horas de incubación (Tubo 4). Los tubos marcados 2,3 y 4 se incubaron por 24 horas a $25^{\circ} \mathrm{C}$ y se les realizó conteo directo en cámara de Neubauer. El control utilizado para este ensayo tuvo el mismo procedimiento pero el medio de cultivo usado fue SGN (SGNM sin Mancozeb).

\subsection{Recuento directo de células en cámara de Neubauer.:}

Para los conteos directos de células en cámara se sirvió una muestra de $10 \mu \mathrm{l}$. El número de células por unidad de área de la rejilla se contó directamente en el microscopio (40X). Se contaron las células presentes en cinco cuadrantes de $4 X 4$, se sumó, promedió y multiplicó por $2.5 \times 10^{4}$ obteniendo el número de células/ml (BOWDEN, 1977)

\subsection{Selección de cepas sensibles a mancozeb}

\subsubsection{Muestreo}

Se tomaron 2 muestras cada una de $500 \mathrm{~g}$ de suelo por medio de calicatas de $25 \mathrm{~cm}$ de longitud, $25 \mathrm{~cm}$ de profundidad y $25 \mathrm{~cm}$ de ancho, de la Vereda Cerezos Grandes "Cerro Bochica" municipio de Chipaque, Cundinamarca y se transportaron al laboratorio de microbiología en bolsas estériles y se refrigeraron a $4^{\circ} \mathrm{C}$ hasta su uso

\subsubsection{Aislamiento de bacterias y prueba de antibiósis para selección de. cepas sensibles a mancozeb}

A $99 \mathrm{ml}$ de caldo nutritivo estéril sé le adicionaron' $11 \mathrm{~g}$ de muestra de suelo, se homogenizó la muestra y se sembró en agar nutritivo en caja, en dilución hasta $10^{7}$ $\left(9 \mathrm{ml}\right.$ de agua peptonada $0.1 \%$ las cajas se incubaron $24 \mathrm{~h}$ a $25^{\circ} \mathrm{C}$. Finalizado el tiempo de incubación se seleccionaron de las cajas con colonias separadas contables, 10 colonias de bacterias que presentarón morfologías macroscópicas y microscópicas diferentes. 
Estas colonias se resembraron por aislamiento en cajas de agar nutritivo y. se incubaron a $25^{\circ} \mathrm{C}$ por $24 \mathrm{~h}$. En una caja de AN con Mancozeb al $0.0625 \mathrm{mg} / \mathrm{ml}$ y otra replica sin mancozeb se sembraron en la superficie una colonia de cada una de las 10 seleccionadas, en posición de acuerdo a una cuadricula de $1 \mathrm{~cm}^{2}$ en papel, la cual se colocó por debajo de las cajas como guía y en correspondencia con la replica. Estos cultivos se incubaron a $25^{\circ} \mathrm{C}$ por $24 \mathrm{~h}$.

\subsubsection{Tiempo de letalidad de la cepa de Bacillus cereus a una concentracion de $0.0625 \mathrm{mg} / \mathrm{ml}$ de mancozeb}

Un inoculo de $10 \mathrm{ml}$ con $10^{7}$ células $/ \mathrm{ml}$ cultivadas previamente por $24 \mathrm{~h}$ a $25^{\circ} \mathrm{C}$ en un caldo mínimo esencial (SGP) (Cloruro de sodio $0.3 \% \mathrm{p} / \mathrm{v}$, Cloruro de Potasio $0.02 \% \mathrm{p} /$ $v$, Sulfato de Magnesio $0.01 \% \mathrm{p} / \mathrm{v}$, Fosfato Monopotásico $0.15 \% \mathrm{p} / \mathrm{v}$, Fosfato de Sodio Bibásico $0.4 \% \mathrm{p} / \mathrm{v}$, Glucosa $1 \% \mathrm{p} / \mathrm{v}$, Peptona $0.1 \% \mathrm{p} / \mathrm{v}$ ), se sembraron por triplicado en tubos con $10 \mu \mathrm{l}$ de medio de cultivo (SGP) suplementado con $0.0625 \mathrm{mg} / \mathrm{ml}$ de mancozeb. Los tubos se incubaron durante 0, 1, $6122436 \mathrm{~h}$ a $25^{\circ} \mathrm{C}$. Terminados los tiempos de incubación correspondientes, se homogenizaron los tubos en vortex y una alícuota de $100 \mathrm{ml}$ se sembró en caja con agar nutritivo por duplicado, utilizando la técnica de recuento"en placa en superficie (ICMSF, 1982). A los tubos control de prueba se les realizó el mismo procedimiento anterior pero no se uso suplemento de mancozeb. Finalmente se realizaron los respectivos conteos.

\subsubsection{Comportamiento de la cepa de Bacillus cereus en SGP a diferentes concentraciones de mancozeb dosis letal 50 (di50), dosis letal 90 (dl90) y dosis letal 100 (dl100)}

Se prepararon 16 grupos de a tres tubos con $10 \mathrm{ml}$ de SGP, $10^{6}$ células $/ \mathrm{ml}$ de Bacillus cereus (proveniente de un cultivo en SGP de $24 \mathrm{~h}$ a $25^{\circ} \mathrm{C}$ ) y mancozeb en las siguientes concentraciones por grupo: $0.0625,0.05,0.0375,0.0250,0.0125,0.01,0.0095$, $0.009,0.0085,0.0075,0.005,0.0035,0.003,0.0022,0.0020,0.0015$ y $0,00 \mathrm{mg} / \mathrm{ml}$. Todos los grupos de tubos fueron incubados a $25^{\circ} \mathrm{C}$ por $24 \mathrm{~h}$. Finalizado el tiempo de incubación se sembró en agar nutritivo por duplicado las diluciones $10^{\circ}, 10^{-1}, 10^{-}$ $2,10^{-3}, 10^{-4}$ y $10^{-5}$, las cajas se incubaron $24 \mathrm{~h}$ a $25^{\circ} \mathrm{C}$ (ICMSF, 1982). Terminado el tiempo de incubación se realizaron los correspondientes conteos de UFC.

\subsubsection{Determinación indirecta de la degradación de mancozeb por hidrólisis en caldo de cultivo SGP usando como indicador la cepa de Bacillus cereus (E5).}

Cuatro tubos con SGP y $0,0625 \mathrm{mg} / \mathrm{ml}$ de mancozeb cada uno fueron incubados a $25^{\circ} \mathrm{C}$ por $24 \mathrm{~h}, 48 \mathrm{~h}, 96 \mathrm{~h}$ y $120 \mathrm{~h}$, respectivamente, por triplicado. Después de incubación, cada uno de los tubos se inoculó con $10^{7}$ células de Bacillus cereus, cultivo fresco de 24 h en SGP. Se utilizó como control de crecimiento de la cepa de Bacillus cereus, 1 tubo con SGP y $10^{6}$ células $/ \mathrm{ml}$ sin mancozeb. Una vez inoculados los tubos, se homogenizaron y se incubaron a $25^{\circ} \mathrm{C}$ durante $24 \mathrm{~h}$. Seguidamente se sembró en caja con agar nutritivo por duplicado en las diluciones $10^{\circ}, 10^{-1}, 10^{-2}$ y se incubaron a $25^{\circ} \mathrm{C}$ durante $24 \mathrm{~h}$. Finalizado el tiempo de incubación se realizaron los correspondientes conteos. 


\subsubsection{Determinación de la Concentración Residual de Mancozeb por degradación biológica con la cepa 8-3 en Medio de Cultivo SM}

Se prepararon 9 tubos cada uno con $10 \mathrm{ml}$ de MS y $0,2 \%$ de nitrato de potasio, se les adiciono $0.0625 \mathrm{mg} / \mathrm{ml}$ de Mancozeb y se les inoculó $10^{7} \mathrm{cel} / \mathrm{ml}$ de la cepa degradadora 8-3, en cada uno. Se incubaron 3 tubos por 0 h, 3 por 24 h y los restantes 3 por 48 $h$ a $25^{\circ} \mathrm{C}$, respectivamente. Terminados los correspondientes tiempos de incubación se homogenizo el contenido de los cultivos, se pasó $1 \mathrm{ml}$ de cada uno y se sirvió respectivamente en otros tubos que contenían $1 \mathrm{ml}$ de caldó SGP'estéril. A estos últimos tubos se les inoculó Bacillus cereus, proveniente de cultivo SGP fresco de 24 h de incubación a $25^{\circ} \mathrm{C}$, para una concentración final por tubo de $10^{6}$ células $/ \mathrm{ml}$. Se homogenizaron y se incubaron los tubos a $25^{\circ} \mathrm{C}$ durante $24 \mathrm{~h}$. Cumplido el tiempo se sembró en cajas con agar nutritivo, por duplicado, diluciones $10^{-1}, 10^{-2}, 10^{-3}, 10^{-4}$ y $10^{-5}$. Las cajas fueron incubadas a $25^{\circ} \mathrm{C}$ por $24 \mathrm{~h}$ y se realizaron los correspondientes conteos de UFC.

Adicionalmente se prepararon controles de antagonismos: A 3 tubos con $10 \mathrm{ml}$ de MS y $0,2 \%$ de nitrato de potasio, se inocularon con $10^{7} \mathrm{cel} / \mathrm{ml}$ de la cepa $8-3$. Un tubo se incubó por $0 \mathrm{~h}$, otro por $24 \mathrm{~h}$ y el tercero por $48 \mathrm{~h}$ a $25^{\circ} \mathrm{C}$. Luego de la incubación correspondiente se homogenizaron y de cada uno de estos se tomó un volumen de $1 \mathrm{ml}$ dispensándolo por aparte en otros tres tubos que contenían $1 \mathrm{ml}$ de medio SGP fresco; a estos últimos tubos se les adiciono $10 \mathrm{mi}$ con una concentración de $10^{7}$ células/ $\mathrm{ml}$ de Bacillus cereus provenientes de un cultivo de $24 \mathrm{~h}$ de incubación a $25^{\circ} \mathrm{C}$. Se homogenizó la mezcla y se incubó por $24 \mathrm{~h}$ a $25^{\circ} \mathrm{C}$, finalizado el tiempo de incubación. se sembró por duplicado placas de AN con diluciones $10^{-1}, 10^{-2}, 10^{-3}, 10^{-4}$ y $10^{-5}$, seguidamente se realizó el corrëspondiente conteo de UFC.

Un control de viabilidad de la cepa E5 se preparó con el mismo procedimiento anterior sin inocular la cepa 8,3.

\section{RESULTADOS Y DISCUSIÓN DE RESULTADOS}

\subsection{Selección de cepas}

Las muestras de suelo provenientes de cultivos de papa se disolvieron en CN con mancozeb al $0.0625 \mathrm{mg} / \mathrm{ml}$ fresco, este método permitió la selección de 69 colonias de bacterias con morfologías macroscópicas diferentes que crecieron a $25^{\circ} \mathrm{C}$ por $48 \mathrm{~h}$. No se presentó el crecimiento de hongos miceliales ni levaduras. Las colonias aisladas fueron sembradas en medio SGNM a $25^{\circ} \mathrm{C}$ por $48 \mathrm{~h}$, este ensayo se realizó en este medio de cultivo para permitir analizar las condiciones de crecimiento con o sin fuentes de carbono (Glucosa $0,1 \%)$ y/o de nitrógeno $(0,2 \%$ de nitrato de potasio) y en presencia o no de mancozeb. Los resultados obtenidos mostraron que las cepas marcadas como 2-2, 6-3 y 8-3 presentaron las mejores dinámicas de crecimiento en estos medios de cultivo. (datos no mostrados). De acuerdo con estos resultados se decidió evaluar el comportamiento de las tres cepas en cultivo estático hasta las 72 horas de incubación utilizando SGNM como medio de cultivo, para conocer la respuesta de los microorganismos al proporcionarles una cantidad de $0.1 \%$ de Glucosa como fuente de carbono y $0.1 \%$ de Nitrato de potasio como fuente de nitrógeno, para así determinar si la población aumentaba una vez agotadas estas fuentes, que pueden ser consumidas en 
18 horas aproximadamente según (TSI) (Triple Sugar Iron). (Manual OXOID. 1995) y así identificar cual de las tres cepas, una vez agotadas estas fuentes, es capaz de tomar el mancozeb como nutriente.

La dinámica de crecimiento de las tres cepas se muestra en la gráfica 1, donde se observa: Un incremento de la población de la cepa 8-3 a través del tiempo confirmando así que ésta degrada el mancożeb para utilizarlo como fuente de nutrición teniendo en cuenta que no hubo suministro de medio de cultivo durante el periodo de incubación del Tubo 1. Sin embargo, se presenta un impacto del mancozeb sobre los microorganismos, evidenciándose en la disminución de la población inicial con respecto al control. En el caso de las cepas 6-3 y 2-2 se presentó un aumento de la población hasta las 24 horas lo que indica, que una vez consumido el $0.1 \%$ la glucosa y el $0.1 \%$ de nitrato de potasio, decrece el número de células por agotamiento de los nutrientes, significando que estas no utilizan el mancozeb. La cepa 6-3 mostró un leve aumento de la población entre las 48 y 72 horas debido posiblemente a que los productos de la lisis celular pueden estar siendo utilizados por las células existentes.

La cepa 8-3 fue clasificada como bacilos Gram negativos, oxidasa positivos, por el métodó de API 20NE con un periodo de incubación de $48 \mathrm{~h}$ Pseudomonas putida con porcentaje de identificación del $65,4 \%$ y con BBL CRISTAL Stenotrophomona maltophilia con un nivel de confianza de 38,4\% (Laboratorio de microbiología ambiental y de suelos. Universidad Javeriana).

Gráfica 1. Dinámica de crecimiento de las cepas $2-2,6-3$ y 8-3 en cultivo estático de SGNM durante $72 \mathrm{~h}$

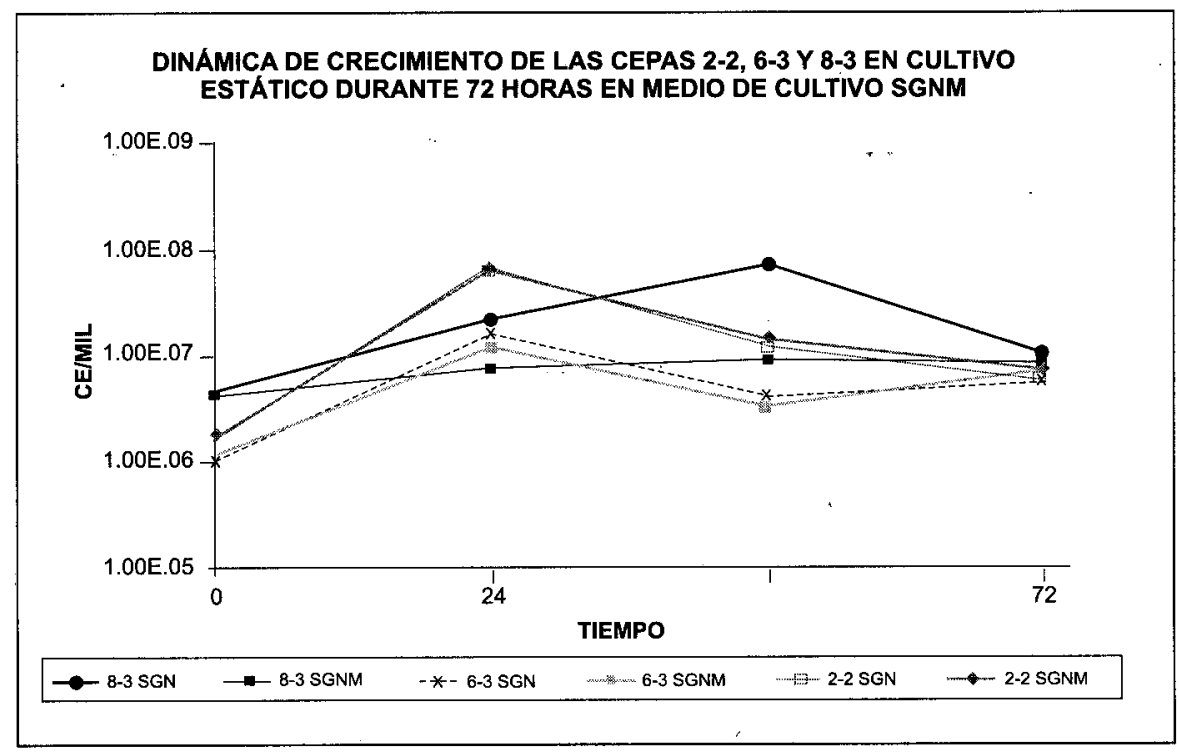




\subsection{Aislamiento de bacterias y prueba de antibiósis para selección de cepas sensibles a mancozeb}

Las empresas que producen el funguicida Mancozeb por sus características de insolubilidad $(0.06 \mu \mathrm{g} / \mathrm{tt}$ ) en agua lo vuelven soluble para ser fumigado sobre el follaje, absorbiéndolo en un compuesto del cual no se conoce su composición por reserva industrial, dicho compuesto es soluble en agua permitiendo una.suspensión del fungicida, la partícula de este compuesto tiene un tamaño parecido al de las bacterias pero es deforma irregular. Cuando se centrífugan los cultivos para retirar las bacterias es precipitado o si se filtran los medios de cultivo con membranas de nitrocelulosa de $0,4 \mathrm{~mm}$ de diámetro es retenido, esta condición disminuye la cantidad de mancozeb presente en el sobrenadante hecho que vuelve compleja la determinación de los residuos de mancozeb en los medios de cultivo cuando se usa el método de HPLC (técnica recomendada que detecta partes por millón de mancozeb), si se quiere saber, si los microorganismos aislados son degradadores de dicho compuesto, se dificultaría estandarizar el método para HPLC con la presencia de microorganismos en las muestras a analizar. Este inconveniente nos llevó a plantear un método utilizando una bacteria sensible al mancozeb para detectar en forma indirecta los residuos de mancozeb en medios de cultivo con bacterias posibles degradadoras de mancozeb. El organismo sensible se aisló de muestras de suelo donde existe poca intervención humana, para asegurar el aislamiento de microorganismos sensibles a un compuesto xenobiótico como el mancozeb. De las muestras de suelo recolectadas en la vereda Cerezos Grandes del municipio de Chipaque, Cundinamarca, se aisló un bacilo Gram positivo esporulado que presentó alta sensibilidad a 0,0625 mg/ml de mancozeb, bacilo clasificado como Bacillus cereus en un $99.6 \%$ por el método Cristal Gram-Positive ID System / GP (Laboratorio de microbiología ambiental y de suelos de la Universidad Javerianal

\subsection{Ensayo 1. Tlempo de letalidad (TL) de mancozeb sobre la cepa e5}

Con este ensayo se determinó que el mancozeb a una concentración de 0,0625mg/ $\mathrm{ml}$ en contacto por espacio de una hora tiene una acción bactericida sobre la cepa E5 (Gráfica 2), llegando a eliminar 100\% de la población por el resultado negativo de UFC en las cajas (tabla 1).

Tabla 1. Recuento UFC/ml de E5 a través del tiempo TL con $0.0625 \mathrm{mg} / \mathrm{ml}$ de mancozeb

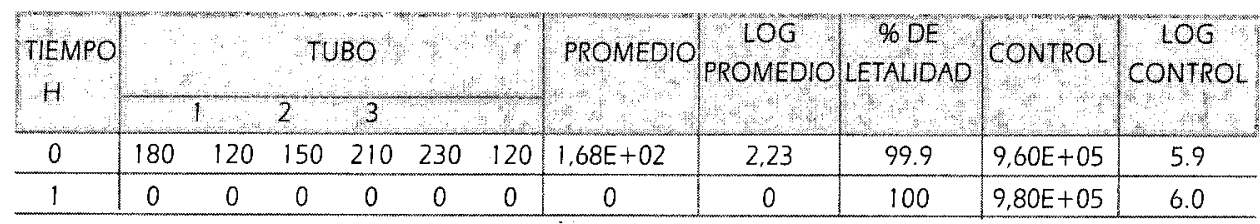


Grafica 2. TL del Mancozeb a $0.0625 \mathrm{mg} / \mathrm{ml}$ frente a la cepa E5

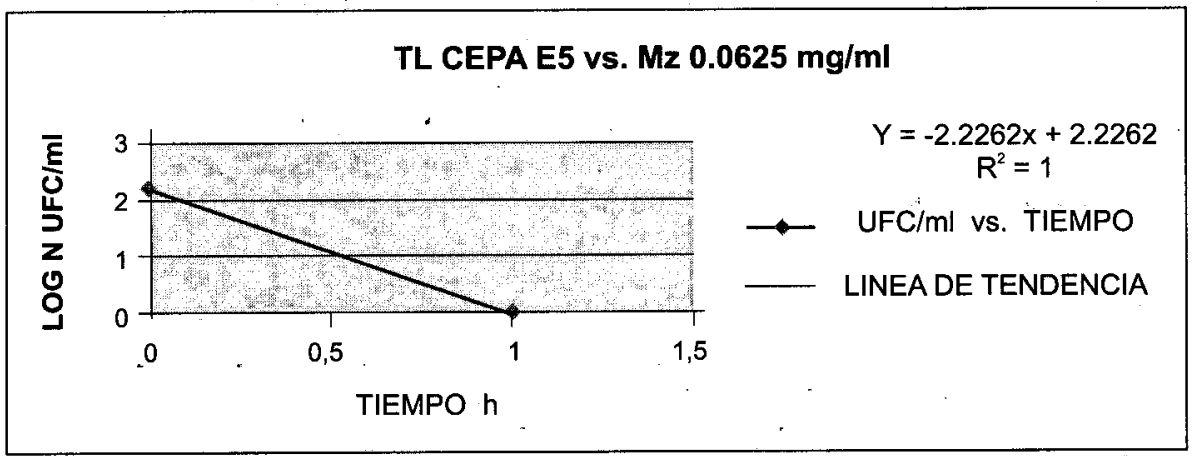

\subsection{Comportamiento de la cepa E5 en medio mínimo esencial a diferentes concentraciones de mancozeb dl50, dl90 y dl100}

Conociendo que el mancozeb tiene un alto nivel de letalidad frente a la cepa E5, se buscaron las dosis letales DL50, DL90 y DL100 para construir la curva patrón que nos permitió obtener las concentraciones residuales de mancozeb en cultivos con 8-3 y nos mostraron si había o no degradación del compuesto, mediante la interpolación del número de células viables de E5.

La tabla 2 muestra los resultados de recuento de colonias de cada una de las concentraciones de mancozeb preparadas. Se omitieron los resultados de las concentraciones $0.0625,0.05,0.0375,0.0250,0.0125,0.01,0.0095,0.009 \mathrm{mg} / \mathrm{ml}$ porque en las siembras sin dilución el resultado fue negativo, indicando la eliminación total de las células a esas concentraciones.

Tabla 2. Recuento UFC/ml a diferentes concentraciones de mancozeb

\begin{tabular}{|c|c|c|c|c|c|c|c|c|}
\hline $\begin{array}{l}\text { MANCO } \\
\mathrm{mg} / \mathrm{m}\end{array}$ & $\mathrm{ZEB}$ & Pras & ${ }^{3}+3$ & TUBO & ${ }^{2}$ & 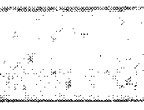 & PROMEDIO & $\begin{array}{l}\text { LOG } \\
\text { PROM }\end{array}$ \\
\hline 0,0085 & 0 & 0 & 0 & $0^{2}$ & 0 & 0 & $0,00 \mathrm{E}+00$ & 0 \\
\hline 0,0075 & 21 & 12 & 18 & 16 & 7 & 21 & $1,58 \mathrm{E}+01$ & 1,20 \\
\hline 0.0050 & $193^{\circ}$ & 209 & 218 & 187 & 182 & 212 & $2,00 E+02$ & 2,30 \\
\hline 0,0035 & $1,00 E+03$ & $2,00 \hat{E}+03$ & $1.00 E+03$ & 0 & $1,00 E+03$ & $1,00 E+03$ & $1,00 E+03$ & 2,96 \\
\hline mats & 2706 & 型 & 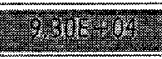 & Solder & 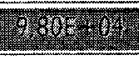 & 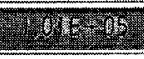 & 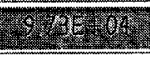 & $\sqrt{29}$ \\
\hline 0,0025 & $3,06 E+05$ & $2,54 \mathrm{E}+05$ & $2,78 \mathrm{E}+05$ & $3,16 \mathrm{E}+05$ & $3,04 \mathrm{E}+05$ & $2,98 E+05$ & $2,93 \mathrm{E}+05$ & 5.47 \\
\hline 0,0022 & 4.80605 & $4,60 \mathrm{E}=05$ & $5,80 \mathrm{E}+65$ & $5.50 \mathrm{E}+05$ & $3.90 E+05$ & $4,80 E+05$ & $4.90 \mathrm{E}+05$ & 5.69 \\
\hline 0.0015 & $1,90 E+07$ & $1,89 E+07$ & $1.29 E+07$ & $1,83 \mathrm{E}+07$ & $1.06 \mathrm{E}+07$ & $9,20 E+06$ & $1,48 \mathrm{E}+07$ & 7,16 \\
\hline 0 & $4.49 E+07$ & $3,12 E+07$ & $3.05 E+07$ & $4,28 E+07$ & $3,26 E+07$ & $3,08 E+07$ & $3.55 E+07$ & 7.55 \\
\hline
\end{tabular}


Los resultados de los recuentos mostraron que la DL100 para la cepa E5 fue de 0,0085 $\mathrm{mg} / \mathrm{ml}$ de mancozeb, la muerte del $90 \%$ de la población se logró con una dosis de 0,003 $\mathrm{mg} / \mathrm{ml}$ de mancozeb y el $50 \%$ de la población se logró eliminar con una concentración de mancozeb de $0.0022 \mathrm{mg} / \mathrm{ml}$. En la gráfica 3 se muestra la línea de tendencia que representa el impacto del mancozeb sobre la cepa E5, lo que nos permitió obtener la ecuación que se utilizó para determinar las dosis letales por interpolación y la degradación del mancozeb por la cepa 8-3:

Gráfica 3. "Recuento de viabilidad de la cepa E5 a diferentes concentraciones de mancozeb

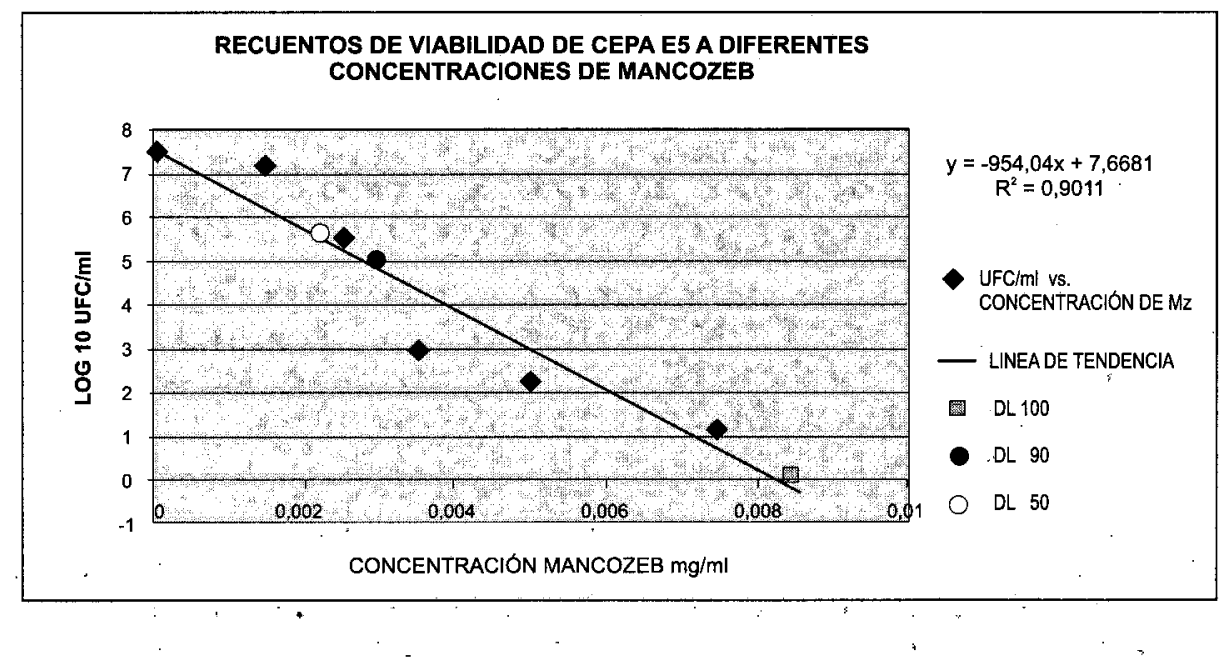

$Y=-954.04 X+7.6681$, siendo $Y$ el log UFC/ml, X la concentración de mancozeb $\mathrm{mg} / \mathrm{ml}$.

\subsection{Determinación indirecta de la degradación de mancozeb por hidrólisis en caldo de cultivo SGP usando como indicador la cepa E5}

Este ensayo se realizó para saber cual es la degradación natural por hidrólisis del mancozeb en medio de cultivo SGP y corroborar los reportes que afirman que el mancozeb se degrada en agua $1-5$ días a $25^{\circ} \mathrm{C}$ en un rango de $\mathrm{pH}$ entre 5-9 en condiciones de oscuridad y esterilidad (R\&H Company. 1987b; Calumpang, et al. 1993; EXTOXNET 1998). 
Tabla 3. Recuento UFC/ml de E5 versus mancozeb a $0.0625 \mathrm{mg} / \mathrm{ml}$ a través del tiempo

\begin{tabular}{|c|c|c|c|c|c|c|c|c|c|}
\hline \multirow{2}{*}{ TIEMPO } & \multicolumn{6}{|c|}{ TUBO } & \multirow{2}{*}{$\begin{array}{l}\text { PROMEDIO } \\
\text { UFC } / \mathrm{m} /\end{array}$} & \multirow{2}{*}{$\begin{array}{c}\text { PROMEDIO } \\
\angle O G\end{array}$} & \multirow{2}{*}{$\begin{array}{l}\text { PROM } \\
\text { CONTROL }\end{array}$} \\
\hline & & 1 & 2 & 0 & 43 & & & & \\
\hline 1 & 0 & 0 & 0 & 0 & 0 & 0 & 0 & 0 & $1 E+06$ \\
\hline 24 & 0 & $\theta$ & 0 & 0 & 0 & 0 & 0 & 0 & $4,77 E+07$ \\
\hline 48 & 0 & 0 & 0 & 0 & 0 & 0 & 0 & 0 & $2.61 E+07$ \\
\hline 72 & 0 & 0 & 0 & 0 & 0 & 0 & 0 & 0 & $2,70 \mathrm{E}+07$ \\
\hline 96 & 4 & 2 & 1 & 2 & 3 & 2 & 3 & 0.48 & $2,53 \mathrm{E}+07$ \\
\hline 120 & 18 & 20 & 15 & 11 & 16 & 18 & 16 & 1.20 & $3,40 \mathrm{E}+07$ \\
\hline
\end{tabular}

En los resultados obtenidos, mostrados en la tabla 3 , se observaron recuentos en las cajas $10^{\circ}$ de la cepa E5 a partir de las $96 \mathrm{~h}$ de incubación de los caldos SGP con mancozeb, Tiempos dentro de los rangos reportados para la hidrólisis en medio acuoso de mancozeb (CORPOICA, 2001, CALUMPANG, et al. 1993, y EXTOXNET, 1998). El recuento promedio fue de $3 \mathrm{UFC} / \mathrm{ml}, \mathrm{n}=6$. Utilizando la ecuación $Y=-954.04 X+7.6681$ se obtuvo la concentración residual del Mancozeb por degradaćión natural en caldo SGP a las 96 y $120 \mathrm{~h}$, correspondiente a 0,0076 y 0,0068 $\mathrm{mg} / \mathrm{ml}$ respectivamente, sugiriendo que a las 120 h el mancozeb no se había degradado en su totalidad, que la acumulación de metabolitos desde las Oh de contacto del mancozeb con el medio de cultivo por degradación natural, no afectó el crecimiento de la cepa E5 y que la presencia de la molécula, compuesto polimérico de Manganeso etilen-1,2-bisditiocarbamato, en coordinación con iones de zinc, fue la causante de la letalidad de la cepa E5.

\subsection{Determinación de la concentración de mancozeb por degradación biológica por la cepa $8-3$ en MS suplementado con $0,2 \%$ nitrato de potasio como fuente de nitrógeno}

Para determinar si la cepa 8-3 estaba involucrada con la biodegradación del mancozeb en medio de cultivo MS con fuente de nitrógeno, se usó la cepa E5 como indicadora de las concentraciones residuales. Un ensayo preliminar demostró que las cepas 8-3 y E5 no fueron antagonistas cuando se mezciaron en medio SGP, los resultados se presentan en las tablas 4 y en la tabla 5 los resultados del control de viabilidad de la cepa E5.

Tabla 4. Recuento viabilidad cepa E5 mezclada con cepa 8-3

\begin{tabular}{|c|c|c|c}
\hline TIEMPO & CONTROL E5 ANTAGONISMO & $\begin{array}{c}\text { PROMEDIO } \\
\text { UFC/mI }\end{array}$ \\
\hline 0 & $3,40 \mathrm{E}+06$ & $2,90 \mathrm{E}+06$ & $3,15 \mathrm{E}+06$ \\
\hline 24 & $8,20 \mathrm{E}+07$ & $6,30 \mathrm{E}+07$ & $7,25 \mathrm{E}+07$ \\
\hline 48 & $6,00 \mathrm{E}+07$ & $5,60 \mathrm{E}+07$ & $5,80 \mathrm{E}+07$ \\
\hline
\end{tabular}


Tabla 5. Recuento vlabilidad cepa E5

\begin{tabular}{|c|c|c|c|}
\hline TEMPO & $\mathrm{CON}$ & $\mathrm{ES}$ & $\begin{array}{c}\text { PROMEDIO } \\
\text { UFCImI }\end{array}$ \\
\hline 0 & $3,70 E+06$ & $3,60 \mathrm{E}+06$ & $3,65 E+06$ \\
\hline 24 & $6,20 \mathrm{E}+07$ & $6,70 E+07$ & $6.45 E+07$ \\
\hline 48 & $5.50 \mathrm{E}+07$ & $7,30 \mathrm{E}+07$ & $6,40 E+07$ \\
\hline
\end{tabular}

Los recuentos no presentaron mayor dificultad ya que las colonias de las dos cepas creciendo en la superficie del agar presentan morfologías macroscópicas diferenciables.

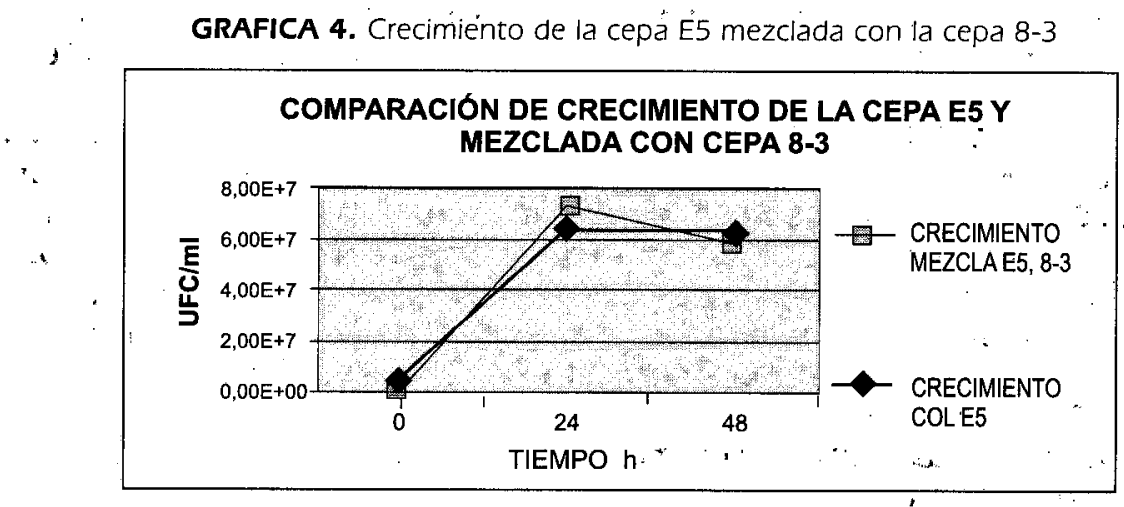

La Gráfica 5, muestra la viabilidad y crecimiento de la cepa E5 cuando creció en presencià de la cepà 8-3 y comparada con el ćcrecimiento cuando creció en cultivo"puro. El resultado obtenido en este ensayo permitió usar la cepa como indicadora de la presencia de mancozeb en los caldos de cultivo.

Grafica 5. determinación de la concentración residual de mancozeb por degradación biológica con la cepa 8-3 mezclada con E5

INTERPOLACION DE DATOS DE LA MEZCLA "A" EN LAFIGURA 2

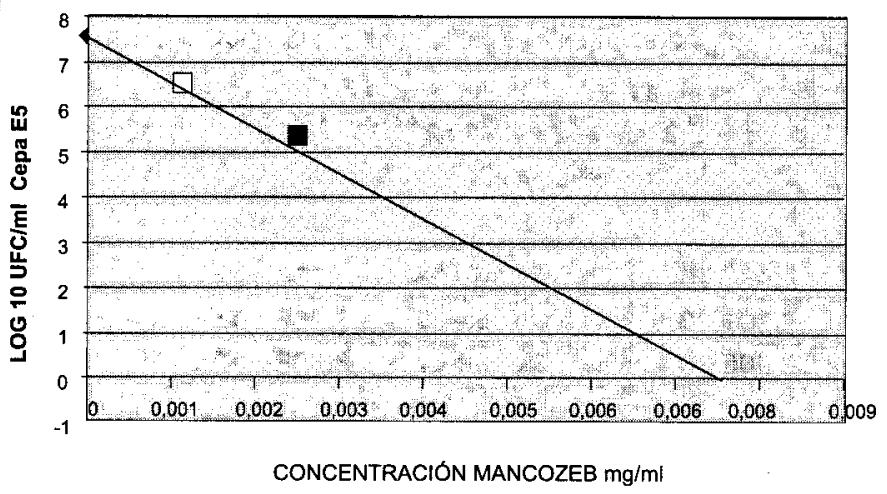

$y=-954,04 x+7,6681$ $R^{2}=0,9011$

Serie 1

- LINEA DE TENDENCIA

CONCENTRACIÓN RESIDUAL DE MzA las $24 \mathrm{~h}$

$\square$ CONCENTRACIÓN RESIDUAL DE $\mathrm{Mz}$ a las $48 \mathrm{~h}$

CONCENTRACION MANCOZEB $\mathrm{mg} / \mathrm{ml}$ 
La tabla 6 muestra los resultados del recuento de UFC/ml la cepa E5 mezclada con la cepa 8-3. Estos tubos contenían a las $0 \mathrm{~h}$ una concentración de mancozeb de $0,0625 \mathrm{mg} / 2 \mathrm{ml}$ que era el Mancozeb total en el tubo, como esta concentración de mancozeb era superior a la DL 100 reportada en este trabajo para la cepa E5, el resultado de conteos negativos es coherente. Los conteos a las $24 \mathrm{~h}$ de incubación de la mezcla, presentaron un promedio de $1,97 \times 10^{5} \mathrm{UFC} / \mathrm{ml}$ de cepa $E 5, n=36$, número de células cercano a la DL50 de reportada en este trąbajo.

Tabla 6. Recuento de UFC/ml de la cepa E5 en mezcla con cepa 8-3

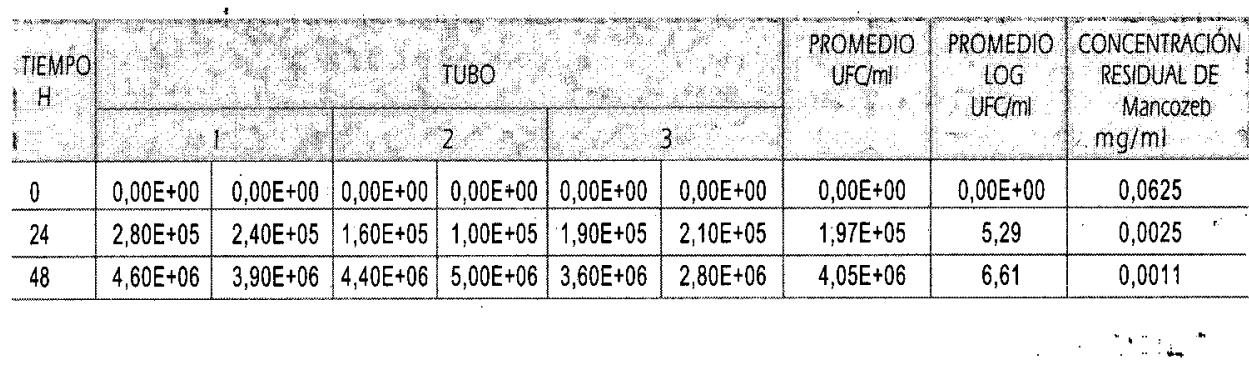

Utilizando la formula $Y=-954.04 X+7.6681$ se determinó que a las 0 h de incubación existe una concentración de mancożeb de $0,0625 \mathrm{mg} / \mathrm{ml}$ y que a las $24 \mathrm{~h}$ es de 0,0025 $\mathrm{mg} / \mathrm{ml}$ y a las $48 \mathrm{~h}$ hia disminuido a $0,0011 \mathrm{mg} / \mathrm{ml}$ significando que la cepa $8-3$ en concentración de un millón de células por mililitro actúa sobre la molécula de mancozeb degradándola (tabla 6, Gráfica 5):

La técnica de cromatografía (HPLC) es la prueba reina para la detección de trazas de pesticidas en agua ý suelos (MOTTA, et al.' 1990; EXTOXNET. 1998), pero las condiciones en que se debe analizar la muestra en el caso de este trabajo dificultan su uso, porque la muestra à anälizar (medio de cultivo con bacterias) se encuentra contaminada con muchos compuestos químicos que pueden alterar la prueba, como son los componentes del medio de cultivo donde se desarrolla el proceso de degradación con la bacteria, metabolitos y los componentes estructurales del microorganismo presente en el medio. Estos no se pueden eliminar por centrifugación ni filtración, debido a las características del Dithane M $45 \mathrm{NT}$, el cual tiene incorporado la molécula de mancozeb en un vehículo que le permite formar una suspensión en medio liquido (GORDON et. al., 1967; EXTOXNET 1998). El vehículo que es uná partícula de tamaño similar al de las bacterias es retenido por filtros de nitrocelulosa de $0.45 \mathrm{~mm}$ y se precipita a la velocidad de centrifugación que se usa para eliminar las células de las bacterias de los sobrenadantes de los cultivos de digestión de mancozeb.

La métodología utilizada para determinar de forma indirécta la degradación biológica de mancozeb, por la cepa de Pseudomonas putida aislada de suelos de cultivos de papa, usando una cepa de Bacillus cereus sensible a mancozeb que no presenta diferencia considerable de mortalidad de células por competencia de nutrientes con la cepa 83, respecto al control de crecimiento de la cepa E5 en cultivo puro, es una alternativa al HPLC e importante como método de tamizaje en la búsqueda de organismos degradadores de pesticidas. Particularmente en el caso del $B$. cereus que presenta esporulación, se puede decir que los métodos utilizados se ajustaron para impedir que 
el organismo esporulara durante los tiempos de incubación usando cultivos frescos de 24 h de incubación y con la revisión microscópica para la búsqueda de esporas.

La cepa aislada degradadora de mancozeb, Pseudomonas putida según los métodos de clasificación utilizados no permitieron la determinación con un porcentaje de seguridad adecuado, por lo tanto se debe realizar una identificación molecular para asegurar el género y especie correspondiente. Si embargo, la cepa muestra una gran posibilidad de ser usada en procesos de remediación de suelos contaminados con mancozeb, por los requerimientos nutricionales mínimos (sales) con la utilización del mancozeb como fuente de carbono y su hábitat original, el suelo propio de cultivos de papa, por su capacidad de crecer en concentraciones de $0,1 \mathrm{mg} / \mathrm{ml}$ de mancozeb y la potencia que presenta para degradar la molécula con una población de un millón de células viables, si se compara con la degradación por hidrólisis natural (Tabla 3), se destaca actividad biodegradadora de mancozeb por Pseudomonas putida (gráfica 6). Las cepas para su conservación se mantienen congeladas a -20 grados centígrados en un sistema CRYOBANK con pasajes cada 6 meses. Este sistema es seguro y muy práctico.

\section{BIBLIOGRAFÍA}

ALDRIDGE, W.N. AND L. MAGOS (1978) "Carbamates, thiocarbamates, dithiocarbamates",Luxembourg, Commission of the European Communities, Report No. $V / F / 1 / 78 / 75 E N$.

BOWDEN, W. B. 1977. Comparison of two direct-count techniques for enumerating aquatic bacteria. Environmental Microbiology 33:1229-1232.

CALUMPANG, S. M. F., M. J. B. MEDINA, N. P. ROXAS AND E. D. MAGALLONA. 1993. Movementand degradation of mancozeb fungicide and its metabolites, ethylenethiourea andethyleneurea in silty clay loam soil, intern. J. of Pest Management, 39(2), 161-166.CORPOICA, 2001. "Validación de componentes para la implementación de un programa de manejo integrado de plagas en el cultivo de la papa". Regional 1 Boyacá-Cundinamarca, Programa Nacional de Transferencia de Tecnología.

EWEIS Y COL, 1998. Tecnologías de remediación biológicas (biorremediación [en línea]: documenting electronic sources on the Internet. [fecha de consulta: 29 de febrero de 2004] Disponible en: http://www.ine.gob.mx/ueajei/publicaciones/libros/372/ tecnolog.html?id_pub $=372$

EXTOXNET (1998) Mancozeb / <AHREF="HTTP: pmep.cce.cornell.edu profiles fugnemat febuconazole-sulfur Mancozeb index.html?

FEDEPAPA, 1996 Federación Colombiana de Productores de papa, Vadenecum del cultivo de papa, primera edición

FRENO, L. H. Y TÉLLEZ, J., 1997. Motivaciones y uso de los plaguicidas en el cultivo de papa. Corporación Colombiana de Investigación Agropecuaria

GONZALEZ, MAURICIO. 2003. Biorremediación y tratamiento de afluentes. [En línea]ilustrados_com.htm. Diciembre 3.. 
GORDON, C. F., SCHUCKERT, R. J. AND BORNAK, W. E.. 1967. Improved method for the determination of etilenebisdithiocarbamato residues in plants, fruit and vegetables. Journal. Assoc. Off. Anal. Chem. 50 : 1102-1108.

ICMSF. MICROORGANISMOS DE LOS ALIMENTOS 1. Técnicas de análisis microbiológico. Ed. Acribia vol. I I. S. B. N 84-200-0517-7 pg 113. 1982

Manual OXOID. 1995. p.249

MOTTA B., RODRÍGUEZ C., MONTENEGRO H., MARULANDA J., CORREA A., BENDECKE M. 1990. Métodos analíticos de laboratorio de suelos. Ministerio de Hacienda y Credito Público. Instituto Geográfico "Agustín Codazzi", Subdirección Agrícola. Bogotá, Colombia. R\&H Company. (1987b). The hydrolytic decomposition of Dithane M-45 at room temperature, DPR Vol. 176-040 \# 53693. Department of Pesticide Regulation, Sacramento, CA.World Health Organization (1988) Dithiocarbamate pesticides, ethylenethiourea, ànd proplenethiourea: a general introduction, United Nations Environment program, the International Labor Organization, and the World Health Organization, Geneva.

$\mathrm{XU}$ Sue, 2000. Environmental fate of mancozeb. Environmental Monitoring \& Pest Management Department of Pesticide Regulation Sacramento, CA 95814-3510. 